\title{
BMJ Open Knowledge, attitude and practice of healthcare professionals towards infliximab and insulin glargine biosimilars: result of a UK web- based survey
}

Stephen R Chapman, ${ }^{1}$ Raymond W Fitzpatrick, ${ }^{1}$ Mohammed I Aladul ${ }^{1,2}$

To cite: Chapman SR, Fitzpatrick RW, Aladul MI. Knowledge, attitude and practice of healthcare professionals towards infliximab and insulin glargine biosimilars: result of a UK web-based survey. BMJ Open 2017;7:e016730. doi:10.1136/ bmjopen-2017-016730

- Prepublication history for this paper is available online. To view these files please visit the journal online (http://dx.doi org/10.1136/bmjopen-2017016730).

Received 7 March 2017 Revised 10 May 2017 Accepted 19 May 2017

CrossMark

${ }^{1}$ School of Pharmacy, Keele University, Hornbeam Building, Newcastle-under-Lyme,

Staffordshire, UK

${ }^{2}$ School of Pharmacy, University of Mosul, Mosul, Nineveh, Iraq

Correspondence to

Prof. Stephen R Chapman; s.r. chapman@keele.ac.uk

\section{ABSTRACT \\ Objective To investigate healthcare professionals' knowledge and attitudes towards infliximab and insulin glargine biosimilars and the factors influencing their prescribing. Then, to compare healthcare professionals' attitudes with the utilisation of these biosimilars in UK hospitals.}

Design Self-administered, one-time web-based survey and drug utilisation analysis.

Setting and data sources Professional associations and societies in the field of dermatology, diabetology, gastroenterology and rheumatology in the UK, between 8 August 2016 and 8 January 2017. The volume of utilisation of branded and biosimilar infliximab and insulin glargine in UK hospitals was derived from the DEFINE database, between 2015 and 2016.

Outcomes Participants' knowledge and awareness of biosimilars and factors influencing their use and corresponding usage of infliximab and insulin glargine biosimilars.

Results Responses were obtained from 234 healthcare professionals across dermatology, diabetology, gastroenterology and rheumatology specialties. $75 \%$ of respondents were aware that biosimilars were available on their local formulary. $77 \%$ of respondents considered biosimilars extremely or very important to save costs for the NHS. Gastroenterologists had the highest utilisation of infliximab biosimilars (14\%) in 2015 rising to $(62 \%)$ in 2016 . Healthcare professionals had greater concerns about safety and efficacy when switching patients to biosimilars than when starting biosimilars in biological naïve patients. Guidance from National Institute for Health and Care Excellence and robust pharmacovigilance studies on biosimilars were both considered important factors in increasing biosimilars use.

Conclusion British healthcare professionals are well informed about biosimilars with high level of awareness. Safety and efficacy concerns were higher in switching than in initiating biosimilars among some prescribers. It is probable that personal experience of biologics as well as discipline-specific guidance influenced prescribers' responses.
Strengths and limitations of this study

Respondents were members of professional associations in gastroenterology, rheumatology, dermatology and diabetology in UK so were judged to be representative of the discipline. There were no financial incentives or inducements to complete the survey.

- Opinions surveyed were those of prescribing consultants only which potentially could lead to bias, but we believe this unlikely as there are no advantage or disadvantages to the individual as a result of negative or positive results to the survey. It was not possible to calculate the response rate from the professional association as the details of members and size of membership are confidential.

- Analyses of national utilisation produced results which reflected the qualitative opinions of the discipline surveyed, implying that the opinions surveyed were representative and generalisable.

\section{INTRODUCTION}

Biosimilars are a non-branded copy of approved and patent expired biological medicines. ${ }^{1}$ The emergence of biosimilars means these less expensive biological medicines have the potential to produce cost savings for the National Health Service (NHS). ${ }^{2}$ Since 2006, 28 biosimilars (corresponding to 11 active molecules) have been licensed in Europe, but the uptake of biosimilars has varied between countries. ${ }^{34}$ It is possible that a variance in understanding among healthcare prescribers of the potential risks and benefits surrounding biosimilars may account for this varied uptake. ${ }^{5}$ With the recent marketing (2015-2017) of biosimilar 'blockbuster drugs' such as infliximab, insulin glargine, etanercept and rituximab, and the European Medicine Agency approval of adalimumab biosimilars (patent expiration in 2018) and the subsequent potentially large cost savings 


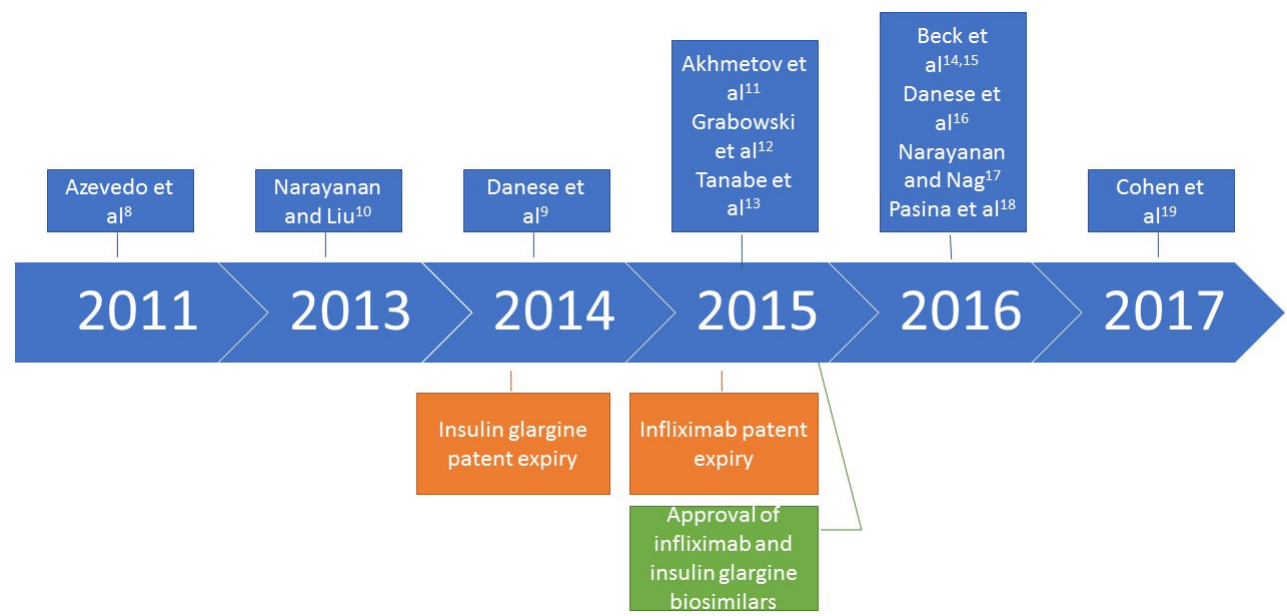

Figure 1 Publication dates of surveys on infliximab and insulin glargine biosimilars.

to health systems, there has been an increased focus on this area of prescribing. ${ }^{36}$ Thus, all healthcare professionals (HCPs) are likely to encounter patients for whom a biosimilar has been or could be prescribed. ${ }^{7}$

The variance in uptake of biosimilars suggests that despite a wealth of clinical and scientific literature, regulatory documents and expert opinion on early approved biosimilars (somatropin, epoetin and filgrastim), HCPs may still have some reservations about using these medicines and more recent biosimilars (infliximab and insulin glargine) in which clinical and non-clinical studies on switching originator to biosimilar are required.

A survey of the literature revealed only 12 studies on HCPs knowledge and understanding on infliximab and insulin glargine biosimilars before and after their introduction (figure 1), and no previous study conducted among HCPs in the UK, which is considered a relatively large market for biological and generic medicines and a potentially attractive market for the biosimilars. ${ }^{8-19}$ Only 3 out of the 12 available studies were conducted in Europe. Narayanan and Liu (2013) and Narayanan and Nag $(2016)^{1017}$ focused on the likelihood of use of biosimilars among rheumatologists, while Danese et al (2016) ffocused on the change in knowledge of biosimilar among inflammatory bowel disease specialists. None of the retrieved studies focused or compared HCPs concerns about safety and efficacy when considering starting biosimilars or switching patients to biosimilars. ${ }^{16}$ To fill this gap in knowledge, this study aimed to explore UK HCPs' knowledge, attitudes and practice towards biosimilars in general and compare and contrast the results with the utilisation of infliximab and insulin glargine biosimilars in hospitals in UK.

\section{METHODS}

\section{Survey design}

This was a non-interventional, anonymised, self-administered, one-time web-based survey among HCPs in the UK. This survey was conducted over 5 months, from 8 August
2016 to 8 January 2017 . This study approved by the Independent Peer Review Committee at Keele University.

\section{Survey sample}

Specialists (consultants, registrars, pharmacists and nurses) in dermatology, diabetology, gastroenterology and rheumatology who were registered members of the British Society of Gastroenterology, the British Society of Paediatric Gastroenterology Hepatology and Nutrition, the Welsh Association for Gastroenterology and Endoscopy, the British Society for Medical Dermatology, the British Society for Paediatric Endocrinology and Diabetes, the Association of British Clinical Diabetologists, the British Dermatological Nursing Group, the Scottish Society for Rheumatology and the British Society for Rheumatology.

\section{Survey procedure}

The survey was a closed survey. A request to distribute an invitation to participate in this web survey was emailed to the professional associations and societies. The invitation letter included a link to the web survey. Reminder emails were sent via the professional associations at 4 weeks after the initial mailing. The survey front page includes information, describing the survey and asking for their voluntary participation. By reading and responding, they gave their consent. The survey questionnaires were designed in such a way that it could not be submitted until all questions had been answered. All the respondents were able to review and change their responses by scrolling up and down the page before submission. Cookies were used by the survey tool allowing only one response per computer. The survey tool was designed to allow only fully completed questionnaires to be submitted for analysis.

\section{Survey questionnaire}

An 11-question questionnaire was developed from emerging themes in the current literature on biosimilars and designed using an electronic website (Survey 
Monkey). The EBSCOhost online research database and PubMed online research database were searched using the terms healthcare professional, physician, doctor, clinician, consultant, registrar, general practitioner, pharmacist, nurse, rheumatologist, gastroenterologist, endocrinologist, diabetologist, dermatologist, survey, web survey, knowledge, attitude, awareness, perception, opinion, experience, behaviour, practice, biosimilar, subsequent entry biologics and me too biologics. Questions were developed to investigate knowledge, experience and opinions towards biosimilars. The survey was piloted on a small number of HCPs and revised appropriately to eliminate redundancy and difficult or ambiguous questions. Questionnaires were not asking any personally identifying information.

\section{Utilisation data}

Data on infliximab and insulin glargine utilisation by specialty in UK hospitals were taken from DEFINE Software since the introduction of infliximab and insulin glargine biosimilars in March and September 2015 respectively to December 2016. The DEFINE software is an NHS prescribing database of medicines usage which collects data from approximately 120 hospitals who subscribe to the software package (covering over 90\% of NHS hospitals throughout the UK including Specialist Centres and Mental Health Trusts). ${ }^{20}$

\section{Statistical analysis}

The survey responses to individual questions were collected, summarised as number and percentage of responding HCPs using Survey Monkey and Microsoft Excel 2013. The percentage of infliximab and insulin glargine biosimilars uptake was calculated using Microsoft Excel 2013.

\section{RESULTS}

\section{Characterisation of participants}

A total of 234 HCPs participated in the survey and responses were relatively evenly distributed between the various specialities. The majority of responses (64\%) $(\mathrm{n}=150)$ were from consultants and registrars. Most of the survey participants $(64 \%, \mathrm{n}=150)$ were general hospital-based HCPs, followed by tertiary centre-based HCPs $(30 \%, \mathrm{n}=70)$, while the remaining were primary care based or in other settings $(6 \%, \mathrm{n}=14)$ (table 1$)$.

\section{Knowledge and awareness of biosimilars}

Most survey participants (72\%) thought biosimilars were similar copies of biological medicines, $18 \%$ thought they were generic biological medicines, $1 \%$ had thought they were new biological medicines and 3\% thought they were counterfeit medicines. A minority (3\%) stated that they had heard about biosimilars but did not know what they were, and $3 \%$ had never heard about biosimilars. A large proportion of the respondents $(75 \%)$ were aware that biosimilars were available on their local formulary (table 2).

\begin{tabular}{llll}
\hline Table 1 & Characteristics of participants & & \\
\hline \multicolumn{2}{l}{ Characteristics } & $\%$ & $\mathbf{n}$ \\
\hline Profession & Consultants and registrars & 64 & 150 \\
& Pharmacists & 11 & 26 \\
& Nurses & 25 & 58 \\
Specialty & Dermatology & 26 & 61 \\
& Diabetology & 25 & 58 \\
& Gastroenterology & 23 & 54 \\
& Rheumatology & 26 & 61 \\
& Primary care & 4 & 9 \\
& General hospitals & 64 & 150 \\
& Tertiary centres & 30 & 70 \\
& Other settings & 2 & 5 \\
\hline
\end{tabular}

\section{Importance of biosimilars prescribing}

Cost saving was the dominant consideration when prescribing biosimilars (figure 2).

\section{Frequency of prescribing biosimilars}

Gastroenterology consultants were the most frequent prescribers of biosimilars (prescribing biosimilars every day or week), followed by rheumatologists and diabetologists. Dermatologists prescribed biosimilars the least frequently (figure 3).

\section{Utilisation of infliximab and insulin glargine}

Analysis of the utilisation of infliximab by specialty in UK showed that compared with other specialties gastroenterologists had the highest utilisation of infliximab (67\%), followed by rheumatologists $(27 \%)$ and dermatologists $(6 \%)$. Further analysis of the utilisation of branded and biosimilar infliximab and insulin glargine by specialty in UK hospitals showed that compared with other specialties gastroenterologists had the highest utilisation of infliximab biosimilars (14\%) in 2015 rising to $(62 \%)$ by 2016 , followed by rheumatologists $6 \%-39 \%$. By contrast, dermatologists had the lowest utilisation of infliximab biosimilars $(6 \%)$ in 2015 and $(35 \%)$ in 2016. Diabetologists' utilisation of insulin glargine biosimilar $(0.5 \%)$ in 2015 and $(9 \%)$ in 2016 were the least in comparison with the utilisation of infliximab biosimilars by HCPs (figure 4).

\section{Perception of safety and efficacy}

The majority of gastroenterology consultants had no or minor concerns about the safety $(95 \%)$ (figure $5 \mathrm{~A}$ ) and efficacy (90\%) (figure 5B) of biosimilars when initiating treatment or when switching patients (95\%) (figure 5C), $(93 \%)$ (figure 5D), respectively. Similarly, a large proportion of rheumatology consultants also had no or minor concerns about safety and efficacy when initiating treatment (92\%) (figure 5A), (88\%) (figure 5B), respectively. In contrast, rheumatologists had major concerns about safety (53\%) (figure 5C) and efficacy (55\%) (figure 5D) when switching patients although these reasons only 
Table 2 Participants' knowledge and awareness

\begin{tabular}{|c|c|c|c|}
\hline Question & Answer & $\%$ & $\mathbf{n}$ \\
\hline \multirow{4}{*}{$\begin{array}{l}\text { Which statement best describes } \\
\text { what you understand a } \\
\text { biosimilar to be? }\end{array}$} & A similar copy of a biological medicine & 72 & 168 \\
\hline & A generic biological medicine & 18 & 42 \\
\hline & A new biological medicine & 1 & 3 \\
\hline & I have heard about biosimilars but I do not know what they are & 3 & 8 \\
\hline \multirow{4}{*}{$\begin{array}{l}\text { Are biosimilars on your local } \\
\text { formulary? }\end{array}$} & Yes & 75 & 174 \\
\hline & No & 9 & 21 \\
\hline & I do not know & 15 & 36 \\
\hline & Not applicable & 1 & 2 \\
\hline
\end{tabular}

prevented a small proportion from switching patients (2\% on safety and $9 \%$ on efficacy) (figure $5 \mathrm{C}, \mathrm{D}$ ).

\section{Factors increasing the use of biosimilars}

Respondents weighted National Institute for Health and Care Excellence (NICE) guidance and robust pharmacovigilance studies on biosimilars equally likely to increase their use of biosimilars. Factors such as local policy, potential cost saving to their organisation and robust cost-effectiveness data for biosimilars versus branded biosimilar medicines were only marginally less important. Cost saving to the respondents' organisation influenced prescribing whether or not these savings were invested in the prescribers' department (figure 6).

\section{DISCUSSION}

Most of UK HCPs that responded (72\%) understood correctly what biosimilars were. A minority thought they were new biologics $(1 \%)$ or generics $(18 \%)$ and only $6 \%$ did not know what biosimilars were (table 2). Our result show that UK HCPs have a comparable level of knowledge about biosimilars to US specialty physicians and a higher level in comparison with Canadian and French rheumatologists and Ukrainian physicians. ${ }^{11} 121419$ Despite this high level of understanding, early prescribing trends of infliximab biosimilars (November 2015) in the UK showed that they were being prescribed in only $45 \%$ of acute trusts with a varied degree of uptake among these trusts. ${ }^{21}$ Our results show infliximab biosimilar usage in NHS hospitals rose from $11 \%$ in 2015 to $55 \%$ in 2016 (figure 4). This considerable increase most likely reflects the views of the majority of HCPs in our study who considered biosimilars prescribing as important for saving costs to the NHS. Given the existing financial pressures within the NHS, this is likely to be a potent driver of prescribing. This is in line with Beck's et al's findings in 2016 that $71 \%$ of French rheumatologists strongly agreed that biosimilars saved costs for their health services. ${ }^{14}$ This financial driver is also implicit in our findings that HCPs held the view that biosimilars are important to stimulate competition in the

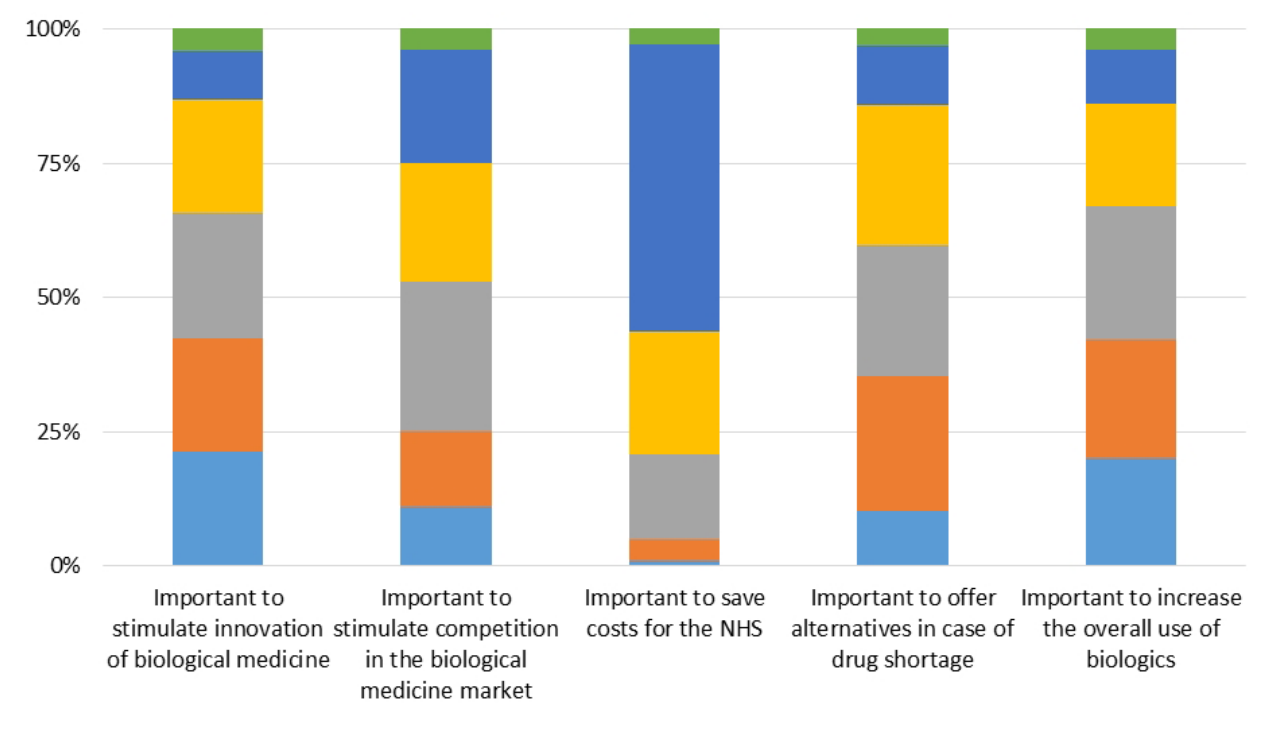

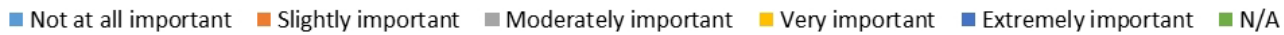

Figure 2 Respondents were asked 'how important are the following factors when considering prescribing a biosimilar?'. 


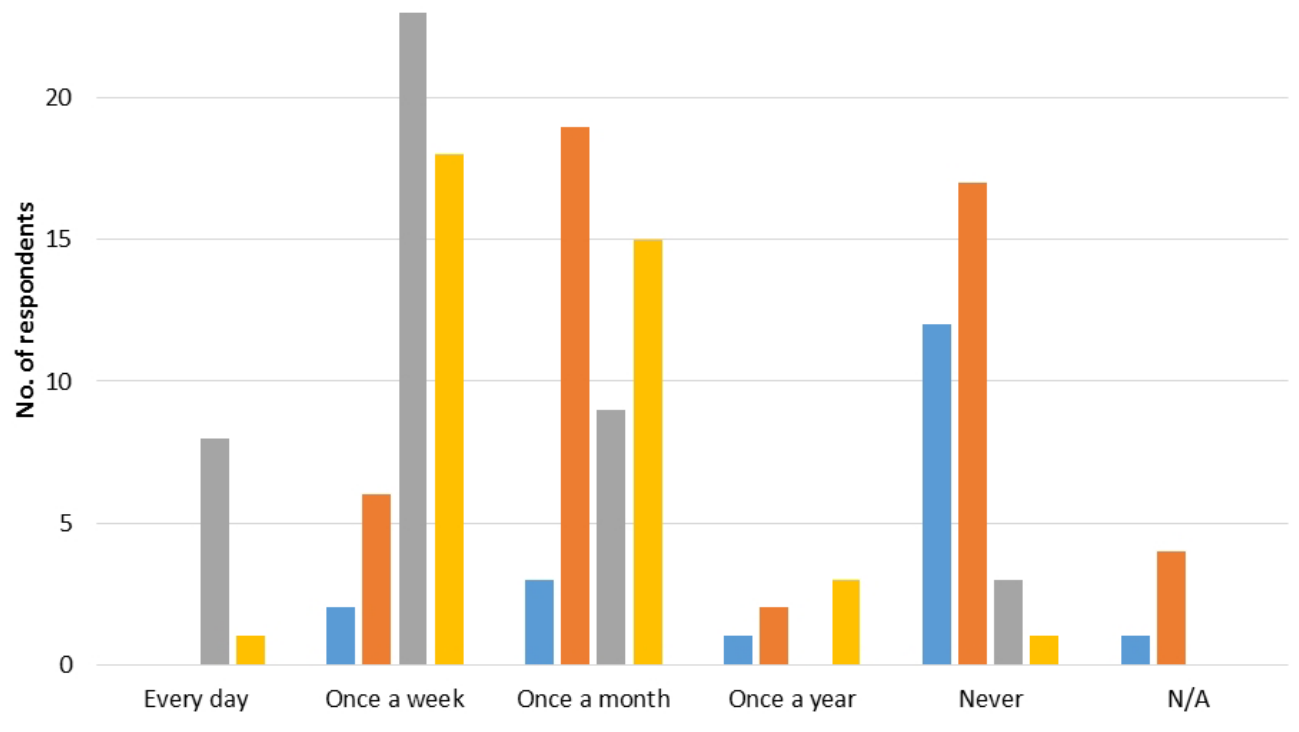

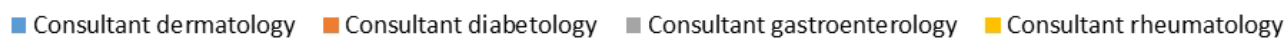

Figure 3 Respondents (consultants) were asked 'how often do you prescribe biosimilars?'.

biological medicine market, since cost competition may lead to downward pressure on prices thus saving costs. ${ }^{22}$

Our survey highlighted a variance in acceptance and utilisation of infliximab biosimilars between specialties with gastroenterologists the most positive followed by rheumatologists and dermatologists the least accepting (figures 3 and 4). This is not surprising since gastroenterologists were the highest users of infliximab, whereas rheumatologists use more other biologics and etanercept biosimilar had only just been marketed. Furthermore, published guidance from the British Society of Gastroenterology supported both initiation and switching to biosimilar infliximab whereas the rheumatology and dermatology professional associations were more cautious as discussed later. ${ }^{23-25}$ Our findings are in line with the result of a survey of the American Gastroenterological Association in 2015, which found that $72 \%$ of gastroenterologists were likely to prescribe biosimilars. ${ }^{26}$

The European Medicine Agency biosimilar approval process involves comparison of the safety and efficacy profiles of biosimilars to their reference biological product. ${ }^{27}$ Nonetheless, HCPs' own perception of the safety and efficacy of biosimilars influenced whether they considered starting a new patient or switching a patient to

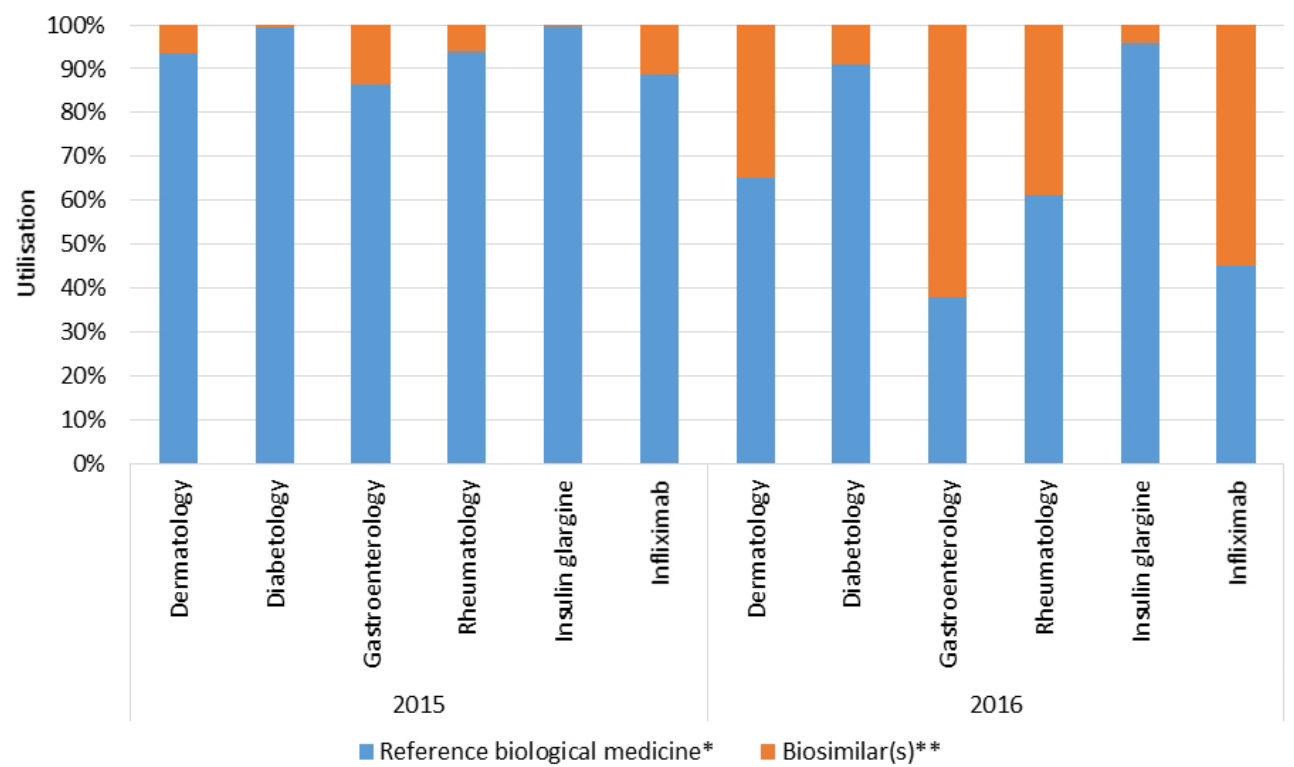

Figure 4 Branded and biosimilar infliximab and insulin glargine utilisation by specialty in UK hospitals between 2015 and 2016. * Reference biological medicine includes infliximab in dermatology, gastroenterology and rheumatology specialty and insulin glargine in diabetology specialty. ${ }^{*}$ Biosimilar(s) includes infliximab biosimilars (Inflectra and Remsima) and insulin glargine biosimilar (Abasaglar), (Flixabi and Lusduna were not included as they have not been used yet in the UK). 
A

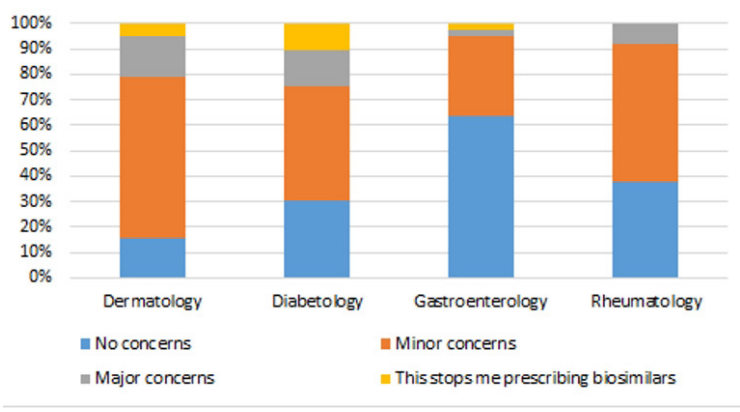

$\mathrm{C}$

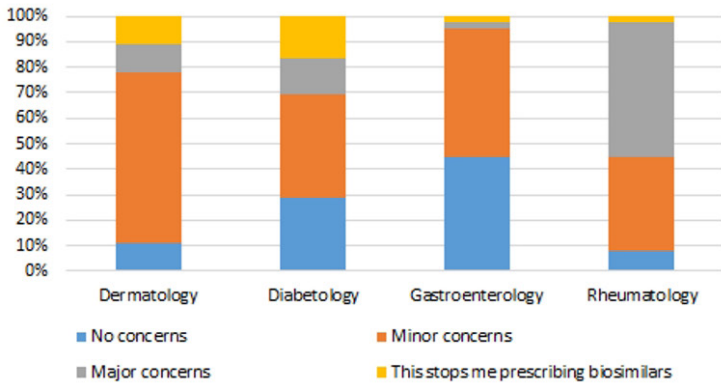

B

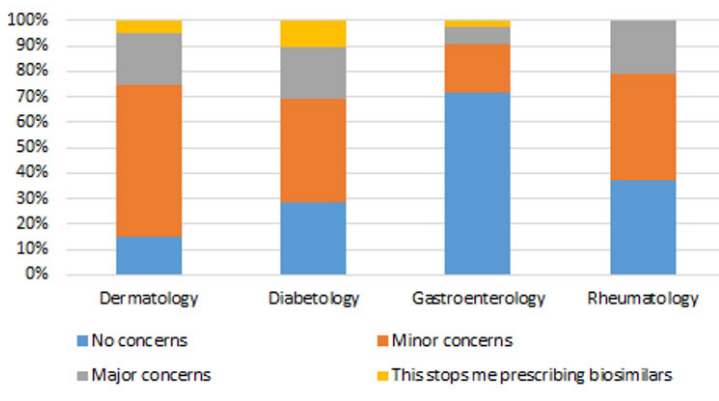

D

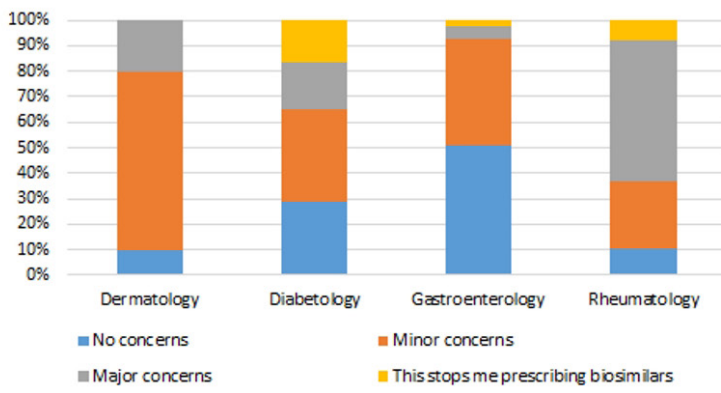

Figure 5 Respondents (consultants) were asked 'how concerned are you about safety and efficacy when considering starting or switching to biosimilars?'. (A) Starting new patients: safety concerns. (B) Starting new patients: efficacy concerns. (C) Switching patients:safety concerns. (D) Switching patients: efficacy concerns.

a biosimilar. ${ }^{28}$ Our survey showed that gastroenterologist consultants have less concerns about safety and efficacy during initiating and switching to biosimilars than other specialties (figure 5), which is in line with the European Crohn's Colitis Organisation survey in 2016 that showed that only a minority of inflammatory bowel disease specialists felt little or no confidence in the use of biosimilars. ${ }^{29}$

While rheumatology consultants were similarly less concerned about efficacy and safety in infliximab naïve patients (figure 5), they expressed more major concerns than other specialties when switching patients from a branded biological medicine to a biosimilar which may reflect their lower use of infliximab. This cautious approach is also evident in the European League Against Rheumatism (EULAR) report (2016) which stated that patients who develop antibodies against Remicade were less likely to benefit from infliximab biosimilars and not suitable for switching. Furthermore, published guidance from the

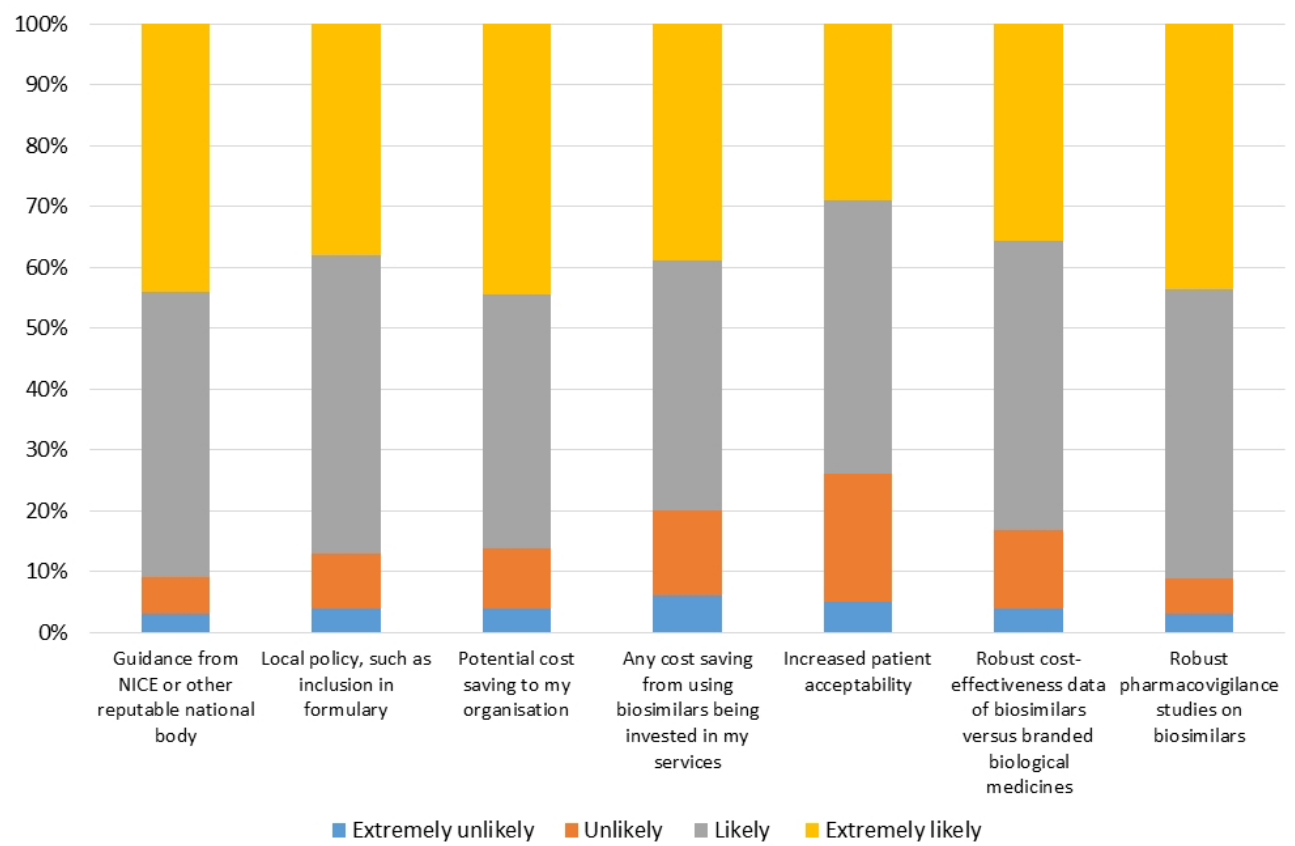

Figure 6 Respondents were asked 'How likely are the following factors to increase your use of biosimilars?'. 
British Society for Rheumatology supports the initiation of new patients on biosimilars, but recommends the decision to switch patients from originator product to a biosimilar should be on a case-by-case basis until further data are available to support safe switching. ${ }^{24}{ }^{30}$ Interestingly, our study found that safety and efficacy concerns only prevented a small proportion of rheumatologists from switching patients to biosimilars $2 \%$ and $9 \%$, respectively.

While the British association of dermatology supports the initiation of new patients on biosimilars but not switching responsive patients to alternatives, our results show only slight differences in dermatologists' opinions of using biosimilars in biological naive patients or switching. This lack of difference in attitude in our survey findings may reflect the fact that dermatologists were relatively low users of biologics compared with other specialties. ${ }^{25}$

A survey of French rheumatologists in 2016 showed that $88 \%$ were prepared to prescribe biosimilars to biological naïve patient, ${ }^{14}$ whereas a survey of European rheumatologists in 2013 showed only $50 \%$ likely to prescribe biosimilars. ${ }^{10}$ Canadian rheumatologists are even more cautious than their European counterparts stating that they were very unlikely or unlikely to prescribe a biosimilars to a biological naive patient. ${ }^{12}$ This variability in approach to biosimilars may be due to the fact that the surveys were conducted before and after the introduction of these biosimilars (figure 1). Interestingly, a survey among USA, France and Germany specialty physicians in 2013 showed that diabetologists/endocrinologists were the least likely to prescribe biosimilars which is similar to our results. ${ }^{31}$ Interestingly, the professional associations for this group have yet to issue any guidance on the use of biosimilars.

Our survey suggests that HCPs attitude towards biosimilars may change with the publication of more robust pharmacovigilance studies on biosimilars similarity and guidance from trusted and reputable bodies such as NICE, which is similar to the results of other studies. ${ }^{16} 19$ Our results also suggest that reinvesting potential savings in local organisations would encourage the uptake of biosimilars also mirrors the results of the European studies. ${ }^{1432}$ Since the British and European professional associations are intertwined and share a similar position towards biosimilars (such as the British society of rheumatology and the EULAR), and the unique biosimilars approval process by the European medicine agency, it is expected that the findings of our survey could be applied to other health systems in Europe or other health systems with similar guidelines.

In view of these responses, a repetition of this survey is needed in the next 1-2 years' time to compare these attitudes following more utilisation of these biosimilars and more publications on switching.

The strength of this study was that we were able to compare and contrast HCPs' attitude towards biosimilars with actual utilisation data. Our study has some limitations. The responses from the professional associations were variable and most of the respondents were consultants/registrars. Only consultants'/registrars' data were used to interpret safety and efficacy concerns (figures 3 and 4) to prevent the results being skewed by non-prescribing healthcare professionals (it is not possible to elicit from the survey whether or not pharmacists and nurses were prescribers). Unfortunately, it was not possible to calculate the response rate as the total number of members of the professional associations and societies are confidential and some HCPs were registered in more than one association or society. Although the number of HCPs in the specialties covered by the survey was not published anywhere, we would estimate that our response rate was low at around $10 \%$, which is a limitation.

\section{CONCLUSION}

UK HCPs have a good understanding of biosimilars and consider biosimilars important as a cost-saving measure. There is significant variation between specialties in their attitude to using biosimilars which is also reflected in actual utilisation data. Gastroenterologists and rheumatologists are more likely to initiate a biosimilar than other specialties but rheumatologists have more concerns than gastroenterologists when switching patients. Despite both groups claiming to be influenced by national guidance from NICE, it is probable that personal experience of the specific biologics as well as discipline-specific guidance influenced their responses.

Correction notice This paper has been amended since it was published Online First. Owing to a scripting error, some of the publisher names in the references were replaced with 'BMJ Publishing Group'. This only affected the full text version, not the PDF. We have since corrected these errors and the correct publishers have been inserted into the references.

Acknowledgements The authors would like to acknowledge all participating associations and societies committees, everyone who provided assistance in the dissemination of the survey, and all participants who completed the questionnaire. The authors would like to thank Zoe Swaine and Jonathan Underhill who participated in the pilot study.

Contributors All authors have contributed to this study, reviewed and approved the final version of the manuscript. SRC designed the study, interpreted the results and reviewed the manuscript and corrected the final version of the manuscript. RWF participated in the study design, interpreted the results and reviewed the manuscript and corrected the final version of the manuscript. MIA participated in the study design, data collection and interpretation of results, prepared the manuscript draft, and performed all analytical testing and manuscript review.

Competing interests None declared.

Patient consent Yes.

Ethics approval Independent Peer Review Committee at Keele University.

Provenance and peer review Not commissioned; externally peer reviewed.

Data sharing statement Data collected from survey are anonymised. The raw data from which result paper are derived can be made available on request.

Open Access This is an Open Access article distributed in accordance with the Creative Commons Attribution Non Commercial (CC BY-NC 4.0) license, which permits others to distribute, remix, adapt, build upon this work non-commercially, and license their derivative works on different terms, provided the original work is properly cited and the use is non-commercial. See: http://creativecommons.org/ licenses/by-nc/4.0/

(C) Article author(s) (or their employer(s) unless otherwise stated in the text of the article) 2017. All rights reserved. No commercial use is permitted unless otherwise expressly granted. 


\section{REFERENCES}

1. Owens DR, Landgraf W, Schmidt A, et al. The emergence of biosimilar insulin preparations---a cause for concern? Diabetes Technol Ther 2012;14:989-96.

2. McCamish M, Woollett G. The rise of the biosimilar. Expert Rev Clin Pharmacol 2012;5:597-9.

3. Agency EM. European public assessment reports. 2017. http:// www.ema.europa.eu/ema/index.jsp?curl=pages/medicines/ landing/epar_search.jsp\&mid=WCOb01ac058001d124\&searchTab= searchByAuthType\&keyword=Enter\%20keywords\&searchType= name\&alreadyLoaded=true\&status=Authorised\&jsenabled=false \& searchGenericType=biosimilars\&orderBy=name\&pageNo=1 (accessed 13 Apr 2017).

4. IMS Institute for Healthcare Informatics. Assessing biosimilar uptake and competition in European markets. [Online]. 2014. Available at https://www.imshealth.com/files/web/IMSH\% 20Institute/Healthcare\%20Briefs/Assessing_biosimilar_uptake_and_ competition_in_European_markets.pdf (accessed 15 Dec 2016).

5. Lai Z, Antonini P, Murphy MF. Demonstrating value for biosimilars: a conceptual framework. 2015.

6. IMS Institute for Healthcare Informatics. Biosimilars Could Save Up to \$110B in EU, USThrough 2020 (Online). 2016. http://www.raps. org/RegulatoryFocus/News/2016/03/29/24671/IMS-BiosimilarsCould-Save-Up-to-110B-in-EU-US-Through-2020 (accessed 15 Dec 2016).

7. Ventola CL. Biosimilars: part 2: potential concerns and challenges for p\&t committees. P T 2013;38:329.

8. Azevedo VF, Felippe LR, Machado DM. Opinion of some brazilian rheumatologists about biosimilars. Rev Bras Reumatol 2011;51:667-71.

9. Danese S, Fiorino G, Michetti P. Viewpoint: knowledge and viewpoints on biosimilar monoclonal antibodies among members of the european crohn's and Colitis Organization. J Crohns Colitis 2014;8:1548-50.

10. Narayanan S, Liu L. Likelihood of use and perception towards biosimilars in Rheumatoid Arthritis Arena: survey of rheumatologists in European Union, Brazil, Japan and China. Value in Health 2013;16:A388-9.

11. Akhmetov I, Farista R, Thimmaraju PK. A study to assess the awareness of the Biosimilars among Ukrainian Physicians. J Bioanal Biomed 2015;7:75-80.

12. Grabowski D, Henderson B, Lam D, et al. Attitudes towards subsequent entry biologics/biosimilars: a survey of canadian rheumatologists. Clin Rheumatol 2015;34:1427-33.

13. Tanabe K, Sugimoto N, Fujimoto Y. A Web-Based survey to investigate the extent of awareness and understanding for biosimilar among Japanese Physicians and Pharmacists. Value Health 2015;18:A658.

14. Beck M, Michel B, Rybarczyk-Vigouret MC, et al. Rheumatologists Perceptions of Biosimilar Medicines prescription: findings from a French Web-Based survey. BioDrugs 2016;30:585-92.

15. Beck M, Michel B, Rybarczyk-Vigouret MC, et al. Knowledge, behaviors and practices of community and hospital pharmacists towards biosimilar medicines: Results of a French web-based survey. Taylor \& Francis: MAbs, 2017
16. Danese S, Fiorino G, Michetti P. Changes in biosimilar knowledge among European crohn's colitis organization (ECCO members: a updated survey. J Crohns Colitis 2016;10: jjw090.

17. Narayanan S, Nag S. Likelihood of use and perception towards biosimilars in rheumatoid arthritis: a global survey of rheumatologists. Clin Exp Rheumatol 2016;34:9.

18. Pasina L, Casadei G, Nobili A. A survey among hospital specialists and pharmacists about biosimilars. Eur J Intern Med 2016;35:e31-3.

19. Cohen H, Beydoun D, Chien D, et al. Awareness, Knowledge, and Perceptions of Biosimilars Among Specialty Physicians. Adv Ther 2017;33:2160-72.

20. Rx Info. Define (Online). 2016. http://www.rx-info.co.uk/products/ define.ashx (accessed at 13 Jan 2017).

21. Alnahar SA, Smith MD, Elliott RA. The uptake of biosimilar infliximab by english acute trusts. Value in Health 2016;19:A265.

22. Cook A, Acton P, Schwartz E. Congressional Budget Office: how increased competition from generic drugs has Affected prices and returns in the Pharmaceutical Industry. Washington: US Government Printing Office, 1998

23. The British Society of Gastroenterology. BSG Guidance on the use of Biosimilar Infliximab CT-P13 in Inflammatory bowel disease (Online). 2016. http://www.bsg.org.uk/images/stories/docs/clinical/guidance/ bsg_infliximab_guidance_16.pdf (accessed 22 Dec 2016).

24. The British Society of Rheumatology. British Society for Rheumatology Position statement on biosimilar medicines. 2017. http://www.rheumatology.org.uk/includes/documents/cm_docs/ 2017/r/revised_bsr_biosimilars_position_statement_jan_2017.pdf (accessed 13 Apr 2017).

25. British Association of Dermatologists. British Association of Dermatologists' Position Statement on Biosimilars. [Online]. 2017. http://www.bad.org.uk/shared/get-file.ashx?id=3615\&itemtype= document (accessed 13 Apr 2017).

26. American Gastroenterology Association. National Survey reveals gastroenterologists' Views on biosimilar drugs. 2015. http://www.gastro.org/press_releases/national-survey-revealsgastroenterologists-views-on-biosimilar-drugs (accessed 19 Dec 2016).

27. Blank T, Netzer T, Hildebrandt W, et al. Safety and toxicity of biosimilars: EU versus US regulation. GaBi J 2013;2:144-50.

28. Camacho LH, Frost CP, Abella E, et al. Biosimilars 101: considerations for US oncologists in clinical practice. Cancer Med 2014;3:889-99.

29. Cummings $\mathrm{f}$. Early experience of switching IBD patients to biosimilar infliximab (Online). 2015. http://www.egaevents.org/presentations/ 2016bios/Fraser_Cummings.pdf (accessed 22 Dec 2016).

30. EULAR. Biosimilar switching not suitable for all patients (Online). 2016. http://www.eular.org/congresspressreleases/Biosimilar switching_not_suitable_for_all_patients_-_OP0015.pdf (accessed 19 Dec 2016).

31. Decision Resources Group's. Biosimilars Advisory Service Acceptance of Biosimilars across Physician Specialties (Online). 2013. https://decisionresourcesgroup.com/get-the-report/141013biopharma-biosimilars-advisory-service-acceptance-of/ (accessed 19 Dec 2016).

32. Karlsberg Schaffer S, Sussex J, Feng Y. Incentives to follow best practice in Health Care, 2015:SSRN 2640041. 